\title{
Tratamiento del bruxismo con toxina hotulínica tipo A. Estudio clínico prospectivo
}

\section{Bruxism treatment with botulinum toxin type A. Prospective clinical study}

\author{
Justo M. Alcolea*, Liza Mkhitaryan**
}

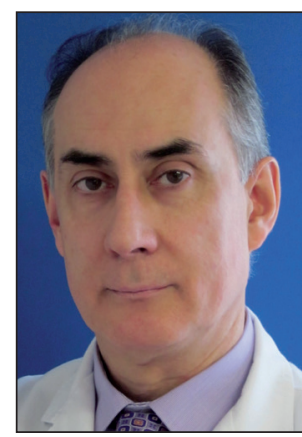

Alcolea J. M.
Resumen

Introducción y objetivo. El bruxismo (BRX) se define como rechinar y/o apretar los dientes, involuntaria e intensamente, debido a hipertrofia y/o contracción reiterada de los músculos masticatorios, especialmentelos maseteros. Puede suceder durante el sueño o de día indistintamente.

Los tratamientos empleados tienen la finalidad de limitar el daño sobre diferentes estructuras biológicas, especialmente la articulación témporo-mandibular (ATM), y oscilan desde oclusión irreversible, interposición de férulas, tratamiento farmacológico y/o terapias cognitivas, así como el empleo de toxina botulínica tipo A (TB-A).

El objetivo de nuestro estudio fue investigar el efecto de relajación inducido por la inyección de TB-A en los maseteros y su relación con el alivio de los síntomas referidos por los pacientes con BRX.

Material y método. Estudio clínico, prospectivo y longitudinal en 25 pacientes, mujeres, de 24 a 67 años (37.2 \pm 10.7$)$, desde setiembre de 2018 a marzo de 2019.Los controles de evaluación se realizaron antes, 2 semanas y 4 meses después del tratamiento con TB-A. Se tomaron fotografías digitales, se valoró el índice de desgaste dental de Smith-Knigth y se realizó ortopantomografía. Algunas pacientes aportaron resonancia magnética nuclear. Se tomaron medidas del diámetro bigonial mediante calibre digital y se valoró el grosor de los maseteros en reposo y contracción,por medición ecográfica.

Resultados. Después del tratamiento con TB-A, el 24\% de las pacientes se vieron libres de BRX y el $76 \%$ restante obtuvo gran mejoría; hubo escasos y transitorios efectos adversos.

Conclusiones. La TB-A protege las estructuras orofaciales (dientes, músculos mandibulares, ATM) del daño inducido por el BRX, al tiempo que alivia el dolor y los síntomas relacionados con la excesiva contracción muscular.

Palabras clave Toxina botulínica tipo A, Bruxismo, Alteraciones temporomandibulares, Desgaste dental, Músculos maseteros

\section{Nivel de evidencia científica Recibido [esta versión] Aceptado}

4c Terapéutico

17 septiembre/2019

10 noviembre/2019
Background and objective. Bruxism (BRX) is defined as grinding or clenching of teeth, involuntarily and intensely, due to hypertrophy and/or contraction of muscles related to chewing, with particular involvement of masseters. It can happen during sleep or wakefulness indistinctly. Treatments are intended to limit destructive effects of BRX on different biological structures, especially the temporomandibular joint; are variable and range from irreversible occlusion, interposition of splints, pharmacological therapies, cognitive-behavioral approaches and the use of botulinum toxin type $\mathrm{A}$ (BoNT-A).

The aim of this study was to investigate the relaxation effect of BoNT-A injection in masseter muscles and its relation to relief of symptoms in patients with BRX

Methods. This study is a clinical, prospective and longitudinal trial on 25 adult female patients between age ranges 24 to 67 (3.2. 10.7), carried out from September 2018 to March 2019.Evaluation controls were done before, 2 weeks and 4 months after treatment with BoNT-A. Examination protocol in the trial included digital photography, Smith and Knight tooth wear index, orthopantomography and magnetic resonance imaging. Measurements of bigonial diameters were taken by calliper, at rest and during contraction, and the thickness of each masseter muscle was also evaluated in the same conditions, by ultrasound at every control.

Results.As a result, after BoNT-A treatment, $24 \%$ of the patients were free of BRX, while the remaining $76 \%$ obtained a significant improvement, with few and transient adverse effects.

Conclusions. BoNT-A can be used to protect oral-facial structures (such as teeth, jaw muscles, temporomandibular joint), from excessive forces and harmful damage caused by BRX, and to relieve accompanying pain and related complaints by decreasing the muscle forces exerted during contraction.

Key words Botulinum toxin type A, Bruxism, Temporomandibular disorders, Dental attrition, Masseter muscle

\section{Level of evidence Received [this version] Accepted}

4c Therapeutic
17 September/2019 10 November/2019

Conflicto de intereses: Los autores declaran no tener ningún interés financiero relacionado con el contenido de este artículo. Financiación: No hubo fuentes externas de financiación para este trabajo.

\footnotetext{
* Master en Medicina Estética.Clínica Alcolea, L'Hospitalet de Llobregat, Barcelona, España.

** Master en Medicina Estética y del Bienestar, Clínica Mona Lisa, Barcelona, España.

Trabajo galardonado con el Premio al estudio más innovador en el 5 Continent Congress, celebrado en Barcelona (España) del 29 de agosto al 1 de setiembre de 2019 en la sección de comunicaciones libres.
} 


\section{Introducción}

El bruxismo (BRX) se define como un trastorno caracterizado por la alteración de los movimientos bucales normales, acompañado por otros no funcionales que conllevan apretar y/o rechinar los dientes y contracturas de uno o más grupos musculares que participan en la masticación. ${ }^{(1,2)}$ La sobrecarga del sistema estomatognático causada por este trastorno tiene efectos perjudiciales sobre los componentes del sistema: dientes, articulaciones temporomandibulares (ATM) y músculos relacionados. ${ }^{(3)}$

De hecho, el BRX se considera el factor de riesgo más importante en la inestabilidad de la ATM.(4) A su vez, las alteraciones en cualquier parte del sistema suponen la afectación en uno o más músculos de los que intervienen en la masticación. Como consecuencia de todo ello, los pacientes pueden referir dolor más o menos agudo durante el proceso de masticación; pero también dolor crónico, movilidad anormal, además de desgaste y fracaso en las restauraciones odontológicas, como en el caso de los implantes dentales. ${ }^{(5)} \mathrm{A}$ la sintomatología anterior cabe añadir cefalea, muchas veces de irradiación atípica. ${ }^{(6)}$ También hay pacientes que perciben el problema como un trastorno estético y su preocupación se debe más a la forma más cuadrada que presenta la cara.

Los síntomas y signos de la alteración de la ATM incluyen: dolor orofacial y preauricular;posible limitación de la apertura de la boca; percepción de clics audibles durante la masticación debido al desplazamiento de los discos articulares; contractura de los músculos maseteros y rechinar de dientes que, cuando es de predominio nocturno, suele referirlo la pareja. ${ }^{(6)} \mathrm{La}$ afectación de la ATM tiene especial relevancia según los nuevos criterios de diagnóstico, como se muestra en la Tabla I.

Las alteraciones de la ATM varían ampliamente, así como la forma en que las personas responden y se adaptan a ellas. ${ }^{(7)}$ Se pueden sistematizar en 3 categorías principales:

1. Síndrome de disfunción con dolor miofascial, que implica sensibilidad o dolor en los músculos que controlan la función de la mandíbula.

2. Alteración intrínseca de la ATM,que consiste en un desplazamiento anterior del disco articular con o sin reducción automática.Se puede acompañar de dislocación de la mandíbula y lesión del cóndilo.

3. Artritis,referida a trastornos articulares degenerativos y/o inflamatorios.

Los factores psicológicos, como el estrés y las características de la personalidad, también se han relacionado con el BRX. ${ }^{(8)}$ Algunas investigaciones muestran que la forma más peligrosa de esta patología es el BRX nocturno, normalmente asociado con problemas de oclusión y trastorno psicoemocional. ${ }^{(9)}$ El estrés, la depresión y la ansiedad son problemas importantes en una sociedad altamente desarrollada. Algunos estudios clínicos sugieren que el estrés, más que el BRX en sí mismo, es la razón

Tabla I. Criterios diagnósticos a tener en cuenta en los diferentes transtornos témporomandibulares.

\section{TRASTORNOS TEMPOROMANDIBULARES}

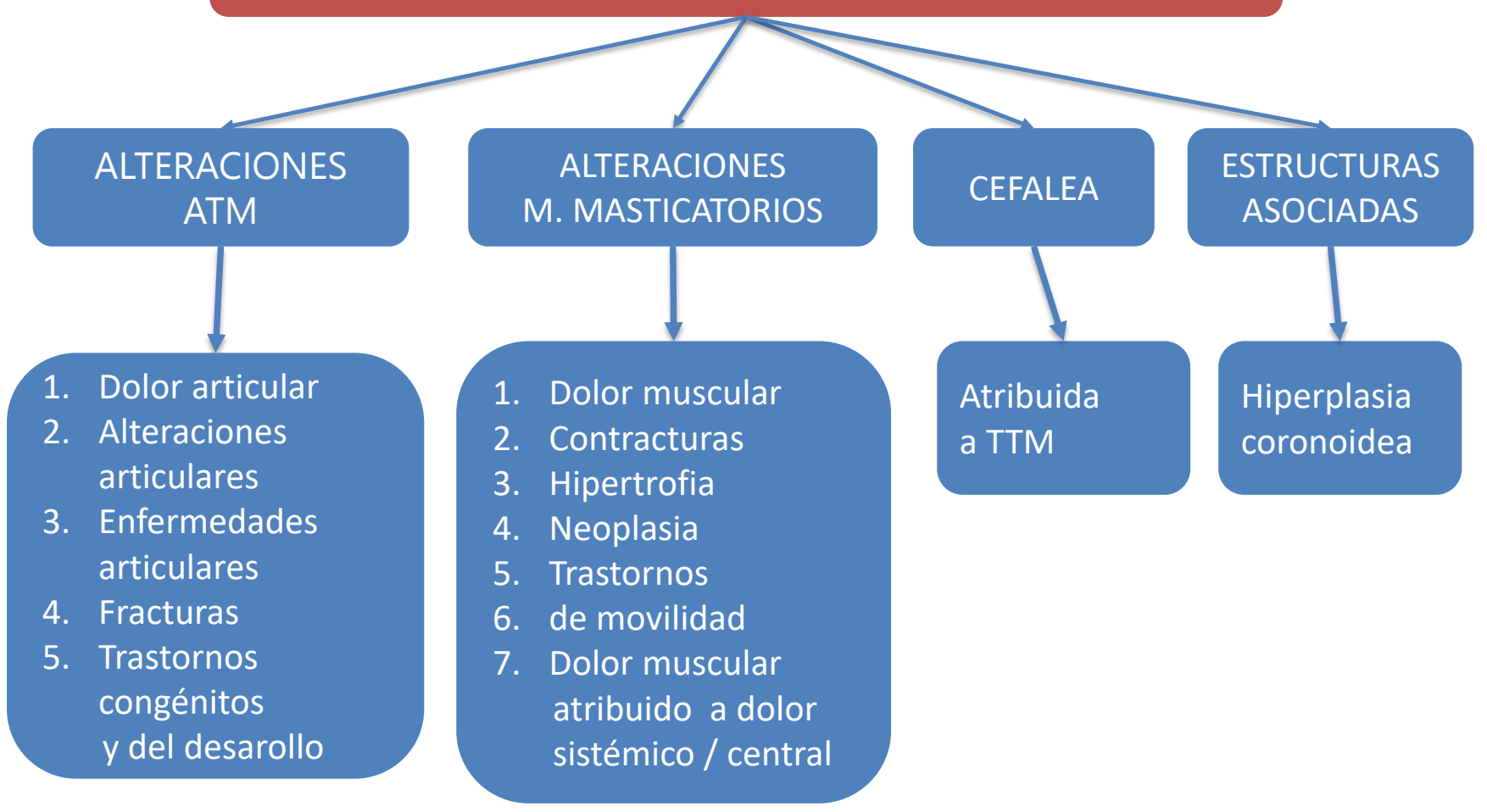

TTM= Transtorno témporomandibular. ATM= Articulación témporomandibular 
principal para que los pacientes busquen consejo médico, especialmente en Estados Unidos. ${ }^{(8)}$

Además de ser una causa desencadenante de alteración de la ATM, el BRX condiciona la aparición de dolores de cabeza y cervicales, llegando a producir trastornos de audición. ${ }^{(4,6)}$

Muchos son los tratamientos propuestos para el BRX, desde la oclusión irreversible, el empleo de férulas de descarga, las terapias farmacológicas o los enfoques cognitivo-conductuales. ${ }^{(9,10)}$ El propósito de todos ellos es limitar los efectos destructivos de este trastorno sobre las estructuras biológicas involucradas. Sin embargo, y teniendo en cuenta que el uso de férulas dentales muestra diferentes grados de eficacia, debe considerarse más un tratamiento sintomático que etiológico, especialmente destinado a prevenir el desgaste dental y la sobrecarga de la ATM. ${ }^{(9)}$ Por otro lado, se ha demostrado que las terapias cognitivo-conductuales tienen efectos poco significativos a corto plazo en el tratamiento del BRX. ${ }^{(8,9)}$ Finalmente, cabe señalar que durante décadas el tratamiento farmacológico del BRX se ha basado en el uso de antidepresivos tricíclicos y benzodiacepinas, hasta que en los últimos años se ha informado de buenos resultados con las inyecciones de toxina botulínica tipo A (TB-A) en los músculos hipertrofiados o con contracciones potentes. ${ }^{(10-13)}$

La TB-A induce la relajación muscular en aquellos músculos en los que se aplica; en el caso de los músculos maseteros disminuye la contracción muscular excesiva, tanto en reposo como durante los movimientos de masticación. El efecto clínico de la TB-A sobre el BRX puede observarse de 2 a 4 días después de la inyección inicial. La duración de sus efectos beneficiosos puede alcanzar hasta 6 meses cuando se realiza el tratamiento por primera vez, y podría ser más duradero si se siguen aplicando nuevas dosis de TB-A periódicamente. ${ }^{(14)}$ No obstante, hay que recordar la posible participación del resto de músculos implicados en la masticación, siendo necesario examinar la participación de los músculos temporales y la de los pterigoideos, aunque es más difícil evaluar el papel que juegan debido a que su palpación es intraoral y el examen mediante ecografía no es accesible. ${ }^{(14,15)} \mathrm{La}$ aplicación de TB-A, en cualquiera de los músculos mencionados, es beneficiosa para reducir los signos y síntomas del bruxismo así como para reducir la hipertrofia muscular si ya se hubiera producido. ${ }^{(14)}$

El uso de TB-A fue aprobado por primera vez en 1989 por la Food and Drugs Aministration (FDA) en EE.UU, para el tratamiento del estrabismo y el blefaroespasmo en humanos mayores de 12 años. ${ }^{(16)}$ Desde entonces, la TB-A se viene aprobando como tratamiento en distintas condiciones clínicas o médico-estéticas, como la distonía cervical en 2000, las líneas faciales glabelares en 2002, la hiperhidrosis axilar en 2004, la migraña crónica en 2010 y las líneas cantales laterales de los ojos en 2013. ${ }^{(17)}$

Existen 7 serotipos diferentes de toxina botulínica, estructuralmente similares pero inmunológicamente distintos, indicados con las letras A, B, C, D, E, F y G, de los cuales el más utilizado y estudiado es el serotipo A. Cada toxina está compuesta de una cadena pesada (H de $150 \mathrm{kDa}$ ) y una ligera (L de $50 \mathrm{kDa}$ ) unidas con un enlace disulfuro e interacciones no covalentes. ${ }^{(18)} \mathrm{El}$ terminal de carbono de la cadena pesada interviene en la unión de la TB-A a la membrana presináptica. Cuando la TB-A se fija a la membrana, se internaliza por endocitosis, mientras que la cadena ligera actúa como la parte tóxica intracelular. ${ }^{(19)}$ La cadena ligera es una endopeptidasa que contiene zinc, capaz de escindir los componentes proteicos de SNARE (N-etilmaleimida soluble receptor de la proteína de unión al factor sensible), una proteína involucrada en el proceso de neuroexocitosis y esencial para la fusión de membranas. ${ }^{(19)}$ El bloqueo con TB-A evita que las vesículas que contienen acetilcolina se fusionen con la membrana terminal de la neurona motora, lo que provoca la interrupción de la transmisión neuromuscular. ${ }^{(18,19)}$

El objetivo del presente estudio es evaluar el efecto de la relajación muscular inducida por la TB-A en una serie de pacientes con bruxismo a través de los controles realizados antes, 2 semanas y 4 meses después de haberse sometido al tratamiento.Para lograr este propósito estudiamos los patrones de hipertrofia muscular mediante ecografía antes y después del tratamiento, teniendo en cuenta los posibles efectos adversos causados por este procedimiento.

\section{Material y método}

En este estudio prospectivo, controlado y longitudinal, se inscribieron 25 pacientes mujeres, de 24 a 67 años (media $3.2 \pm 10.7$ ). Todas presentaban diversas molestias como dolor y/o tensión, especialmente al levantarse de la cama; algunas también se quejaron de dolor leve ocasional durante la masticación. También hubo pacientes que percibían su contorno facial como de forma más cuadrada.

Llevamos a cabo el estudio entre septiembre de 2018 y marzo de 2019 en la Clínica Alcolea (L'Hospitalet de Llobregat, Barcelona, España) y la Clínica Mona Lisa (Barcelona, España).

Las pacientes evaluadas, al ser preguntadas por la presentación del BRX en relación con el ciclo circadiano, refirieron que: 1 solo lo padecía despierta, 6 lo sufrían durante el sueño, y las 18 restantes presentaban BRX tanto diurno como nocturno. 

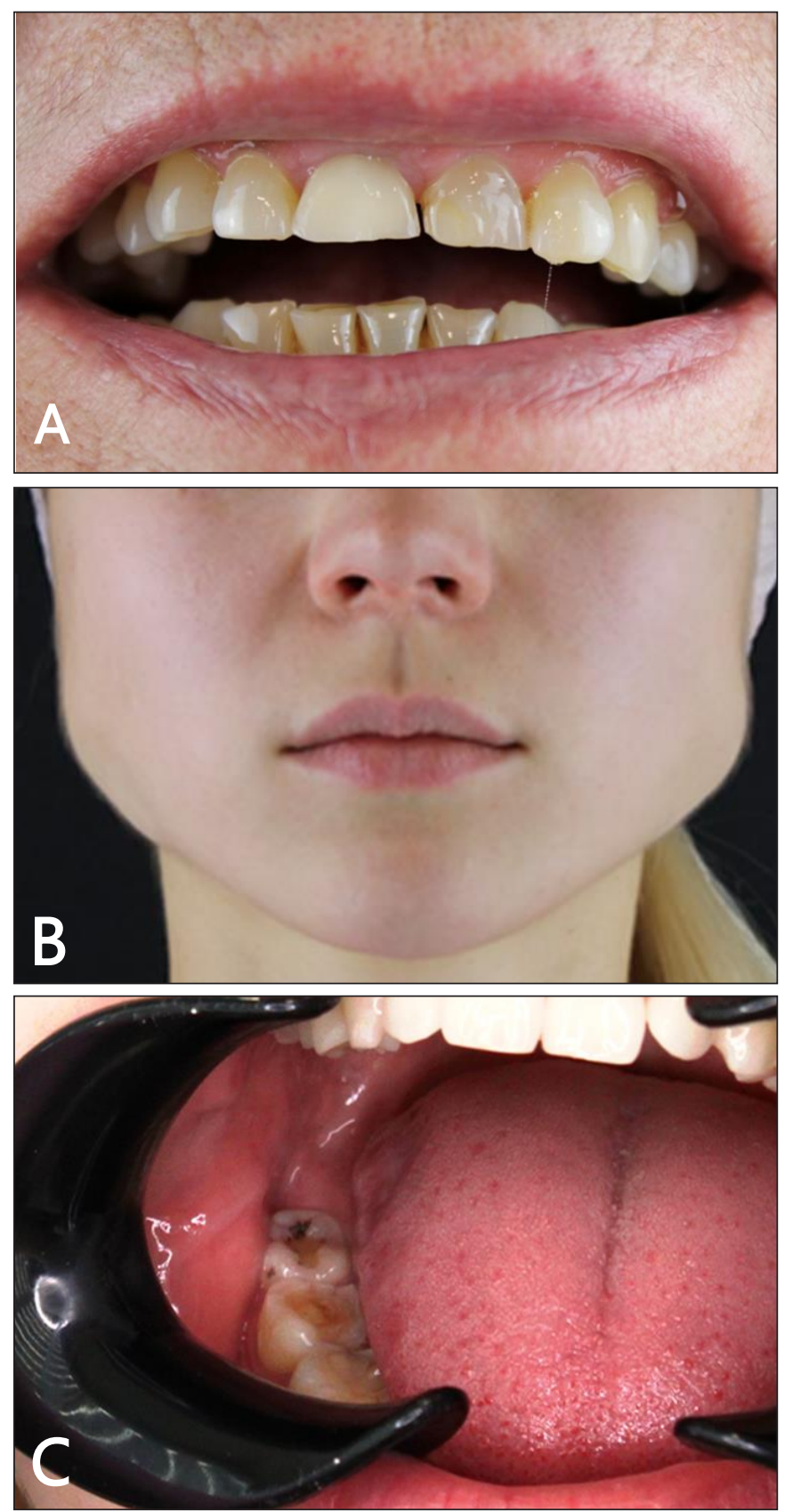

Figura 1. A. Desgaste dental secundario a bruxismo. B. Hipertrofia muscular en contracción forzada de los masteros, con aspecto de mandíbula cuadrada. C. Impronta dental típica apreciable en la lengua.

Para este estudio tuvimos en cuenta los siguientes criterios:

1. Presencia de signos secundarios, como el desgaste dental, rechinar o apretar en exceso los dientes (Fig.1 A).

2. Presencia de hipertrofia muscular de músculos maseteros en la contracción voluntaria (Fig.1 B).

3. Molestias a nivel de músculos de la masticación (con posible irradiación a estructuras vecinas), dolor, fatiga o rigidez al movilizar la mandíbula tras levantarse de la cama.

4. Hipersensibilidad en los dientes.

5. Audición de clics o chasquidos o sensación de bloqueo de la ATM.

6. Impronta dental con o sin sangrado en la lengua y/o mejillas (Fig.1 C).
Realizamos los controles y evaluaciones de las pacientes antes del inicio del tratamiento y 2 semanas y 4 meses después del tratamiento con TB-A.

A todas se les preguntó si recomendarían el tratamiento a sus familiares y amigos y si continuarían con nuevas sesiones de tratamiento. Todas fueron informadas sobre los procedimientos a los que se someterían y otorgaron su consentimiento por escrito para participar en el estudio.

\section{Evaluación de las pacientes.}

1. Tomamos imágenes frontales con una cámara digital $\left(\right.$ Canon $^{\circledR}$, D2000, Canon Inc, Tokio, Japón) en estado de relajación y contracción antes de iniciar el tratamiento y a las 2 semanas y 4 meses después de realizado.

2. Valoramos el índice de desgaste dental. Smith y Knight $(1984)^{(20)}$ definieron el índice de desgaste dental (TWI:Tooth Wear Index) como un sistema integral en el que las cuatro superficies visibles (bucal, cervical, lingual y oclusal-incisal) de cada uno de los dientes presentes se clasifica de acuerdo al desgaste encontrado, independientemente de sus causas (Tabla II).

3. La ortopantomografía (OPG) es una técnica que muestra con precisión las estructuras óseas de la ATM y es el método adecuado de detección de las alteraciones internas de la articulación. Permite diagnosticar y valorar:

a. Alteraciones óseas degenerativas.

b. Alteraciones patológicas inespecíficas.

c. Clasificación del grado de las alteraciones patológicas.

d. Eficacia de las medidas terapéuticas realizadas.

e. Técnica diagnóstica primaria de la ATM (fracturas, quistes, tumores, inflamación, aplasia, hipoplasia, hiperplasia y alteraciones degenerativas). ${ }^{(21)}$

4. Indicamos resonancia magnética nuclear (RMN) como método de imagen más exhaustivo en el diagnóstico de los trastornos témporo-mandibulares.

No obstante, de las 25 pacientes que participaron en el estudio solo 3 realizaron RMN debido a varios motivos: el alto costo de la prueba, la incomodidad de realizar el procedimiento y el temor a un exceso de radiación.

5. Medimos el diámetro bigonial (distancia entre ambos ángulos mandibulares) con calibre digital, en relajación y contracción máxima de los músculos maseteros. Esta medida complementa y se correlaciona bien con la medición ecográfica de cada músculo masetero (Fig. 2).

6. Realizamos medición ecográfica. Los músculos maseteros contribuyen de manera decisiva al cierre de la boca y se considera que lo hacen de modo principal a la aparición del BRX, aunque la participación de los mús- 
Tabla II. Grados y criterios del índice de desgaste dental de Smith y Knight en relación a las superficies dentales:

B, bucal; L, lingual; O, oclusión; I, incisal; C, cervical.

\begin{tabular}{|c|c|c|}
\hline Grados & Superficie & Criterios \\
\hline 0 & $\mathrm{~B} / \mathrm{L} / \mathrm{O} / \mathrm{I} / \mathrm{C}$ & $\begin{array}{l}\text { Sin pérdida de las características del esmalte } \\
\text { Sin pérdida de contorno }\end{array}$ \\
\hline 1 & $\mathrm{~B} / \mathrm{L} / \mathrm{O} / \mathrm{I} / \mathrm{C}$ & $\begin{array}{l}\text { Pérdida de las características del esmalte } \\
\text { Pérdida mínima de contorno }\end{array}$ \\
\hline 2 & $\mathrm{~B} / \mathrm{L} / \mathrm{O} / \mathrm{I} / \mathrm{C}$ & $\begin{array}{l}\text { Pérdida de esmalte que expone la dentina en menos de } 1 / 3 \text { de la superficie } \\
\text { Pérdida de esmalte simplemente exponiendo dentina } \\
\text { Defecto de menos de } 1 \mathrm{~mm} \text { de profundidad }\end{array}$ \\
\hline 3 & $\mathrm{~B} / \mathrm{L} / \mathrm{O} / \mathrm{I} / \mathrm{C}$ & $\begin{array}{l}\text { Pérdida de esmalte que expone la dentina en más de } 1 / 3 \text { de la superficie } \\
\text { Pérdida de esmalte y pérdida sustancial de dentina } \\
\text { Defecto de menos de } 1-2 \mathrm{~mm} \text { de profundidad }\end{array}$ \\
\hline 4 & $\mathrm{~B} / \mathrm{L} / \mathrm{O} / \mathrm{I} / \mathrm{C}$ & $\begin{array}{l}\text { Pérdida completa del esmalte y exposición pulpar secundaria } \\
\text { Exposición pulpar o exposición de dentina secundaria } \\
\text { Defecto de } 2 \mathrm{~mm} \text { de profundidad y exposición pulpar secundaria a dentina }\end{array}$ \\
\hline
\end{tabular}
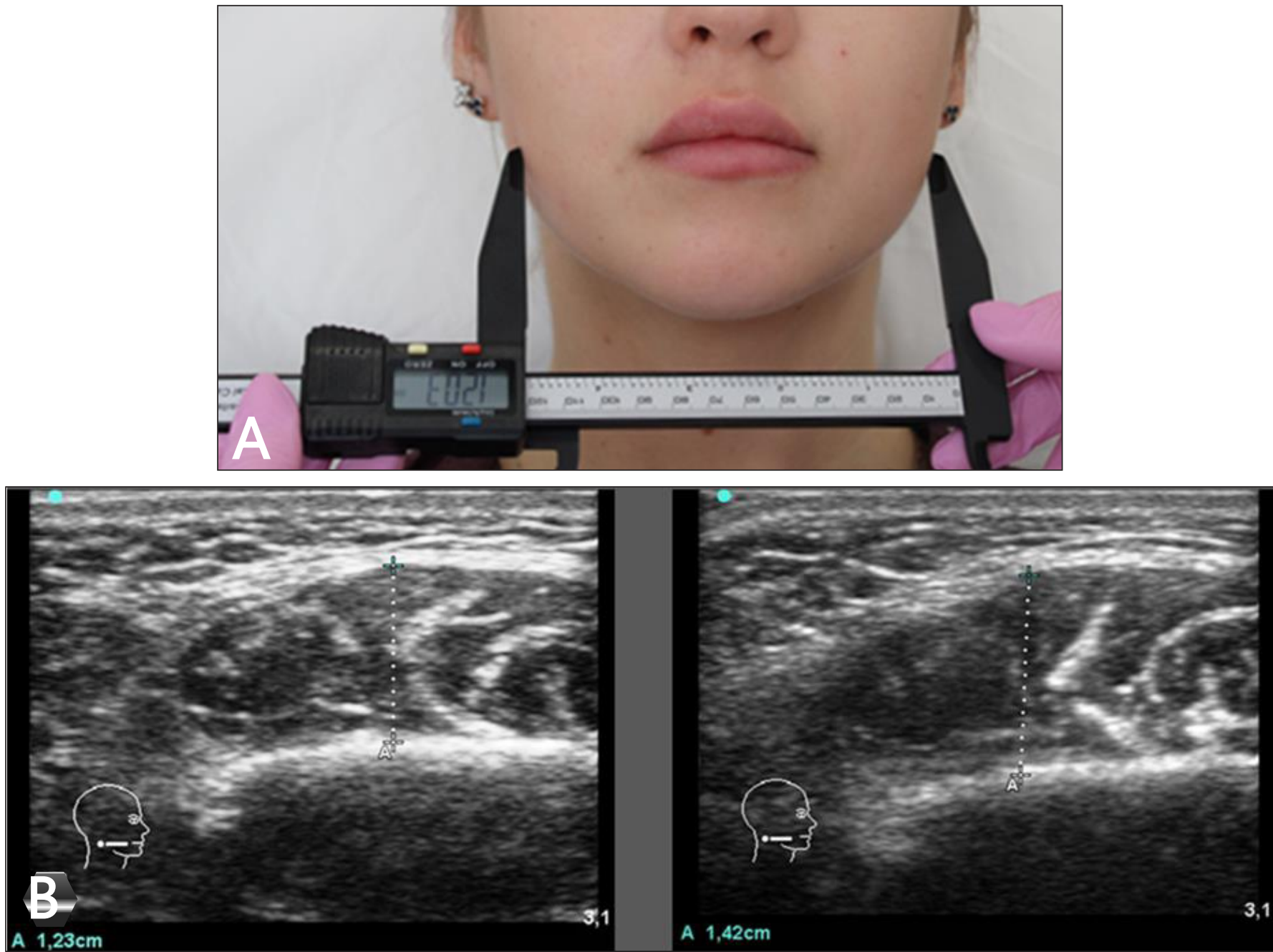

Figura 2. A. Medición del diámetro bigonial mediante calibre de puntas largas en una paciente de 24 años ( $\mathrm{n}^{\circ} 22$ del estudio). B. Medidas tomadas por ecografía del masetero derecho, en relajación y contracción, de la misma paciente. 
culos temporales y pterigoideos tampoco debe infravalorarse. El estudio ecográfico de cada músculo masetero es importante para cuantificar la diferencia de grosor en relajación y en contracción máxima. ${ }^{(22)}$

Llevamos a cabo las mediciones con un equipo Sonosite $^{\circledR}$ (Sonosite Inc, Irvine-CA-, EE.UU.), empleando un transductor multifrecuencia de 7 a $12 \mathrm{MHz}$. El transductor de ultrasonido se colocó en posición paralela a la rama mandibular, unos $2 \mathrm{~cm}$ por encima de su borde inferior. Las medidas ecográficas se tomaron con el paciente sentado y sin comprimir la sonda contra la piel de la cara.

\section{Técnica de inyección}

Inyectamos la TB-A (Azzalure ${ }^{\circledR}$, Galderma SA, Madrid, España) en cada masetero de forma bilateral, previa aspiración a fin de evitar la inyección intravascular. El frasco de Azzalure ${ }^{\circledR}$ (125 US) se reconstituyó con $1 \mathrm{ml}$ de solución salina fisiológica para lograr una difusión más homogénea en los músculos inyectados. Aplicamos la TB-A mediante jeringa de insulina con aguja incorporada $30 \mathrm{G}$ de $12 \mathrm{~mm}$ (Braun ${ }^{\circledR}$, Melsungen, Alemania).

Estimamos las unidades de TB-A utilizadas en cada paciente después de las mediciones ecográficas de cada músculo masetero en reposo y máxima contracción. En general, variaron de 7.5 a 10 Unidades Speywood (US) por punto de inyección. Las dosis totales fueron de 30 a 95 US por paciente (media $57 \pm 18$ ). Determinamos los puntos de inyección y las unidades de tratamiento en virtud de la potencia exhibida por cada uno de los 3 fascículos musculares. Las inyecciones se realizaron en 3 puntos localizados en el tercio inferior del músculo masetero (Fig.3).

Solo 4 de las 25 pacientes del estudio requirieron una segunda inyección de TB-A, de 5 a 7.5 US, en alguno de los fascículos del masetero. Realizamos la segunda inyección 2 semanas después de la primera, coincidiendo con la visita de control.

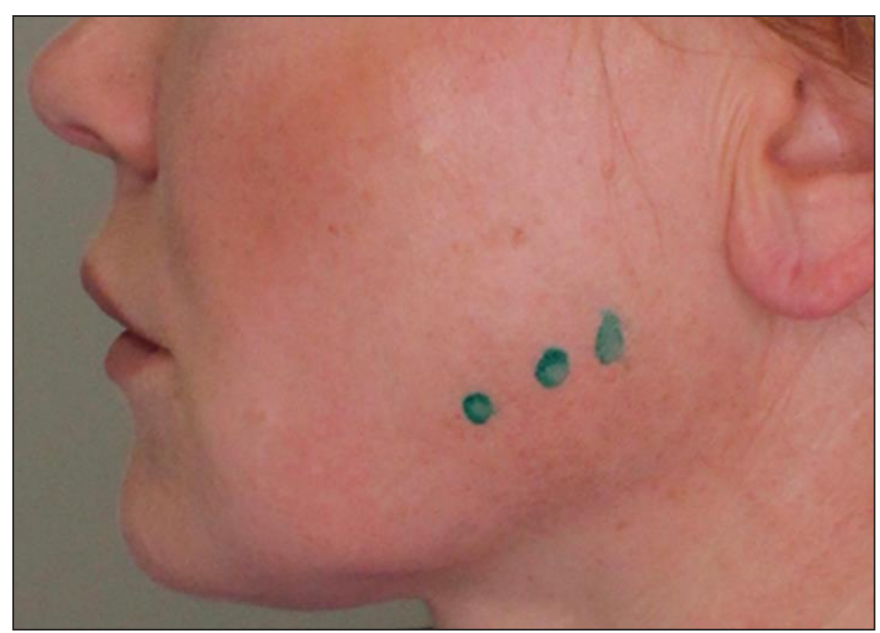

Figura 3. Puntos guía para la inyección de la TB-A en el masetero izquierdo, según la disposición de los fascículos, empleados en la paciente $n^{\circ} 25$ del estudio.

\section{Valoración de resultados}

Cuantificamos la valoración del tratamiento del BRX con TB-A de la siguiente manera: 0 , sin mejoría; 1 , ligera mejoría; 2 , mejoría moderada; 3 , mejoría significativa; 4 , libre de bruxismo. Asimismo, cuantificamos entre 0 y 4 cada uno de los posibles efectos adversos presentados: 0 , sin efectos adversos; 1 , leves; 2 , moderados; 3 , severos, y 4 , muy severos. También tuvimos en cuenta la satisfacción de los pacientes, valorándola de 0 a 4 : siendo 0 , no satisfecho y 4 muy satisfecho.

\section{Análisis estadístico}

Utilizamos el programa SPSS v.20 para Windows. Tuvimos en cuenta la media, el mínimo y el máximo, el rango, el porcentaje (\%) y la desviación estándar (DE). Se establecieron intervalos de confianza y se realizó un análisis multivariante para muestras relacionadas (prueba T de Student). Consideramos estadísticamente significativo un valor de $\mathrm{p}<0.05$.

\section{Resultados}

Los datos analizados, con excepción de la edad, muestran pequeñas desviaciones estándar con poca dispersión respecto a la media aritmética, lo que indica que esta es representativa de la muestra analizada.

Con esta premisa y para reducir el número de variables sin perder información, realizamos un estudio comparativo entre los valores ecográficos obtenidos de ambos músculos maseteros, en relajación y contracción, y utilizamos la prueba $\mathrm{T}$ de Student para muestras relacionadas. Las ecografías mostraron que existe una diferencia significativa entre las mediciones de los maseteros en relajación $(1.21 \mathrm{~mm} \pm 0.23)$ y en contracción $(1.53 \mathrm{~mm} \pm 0.24)$ obtenidas antes del tratamiento y las encontradas 2 semanas después (relajación: $1.06 \mathrm{~mm} \pm 0.24$; contracción: 1.25 $\mathrm{mm} \pm 0.28)$. Sin embargo, no hubo diferencia significativa $(\mathrm{p}>0.05)$ entre las medidas de control de 2 semanas y las de 4 meses después (reposo: $1.08 \mathrm{~mm} \pm 0.19$; contracción: $1.29 \mathrm{~mm} \pm 0.20$ )(Fig. 4). De la misma manera se procedió con la variable diámetro bigonial: la diferencia fue significativa $(\mathrm{p}<0.05)$ entre los valores de antes del tratamiento (122.8 $\mathrm{mm} \pm 5.6)$ y los de 2 semanas después $(119.1 \mathrm{~mm} \pm$ 5.6), pero no la hubo entre los resultados de 2 semanas y los de 4 meses después del tratamiento $(119.4 \mathrm{~mm} \pm 6.0)$ (Fig.5). Tanto las medidas ecográficas como las del diámetro bigonial presentaron similar evolución.

Es de destacar que 6 pacientes (24\%) quedaron libres de bruxismo; el resto (76\%) experimentó una mejoría significativa. Por lo tanto, todas las pacientes tuvieron muy buenos o excelentes resultados, respondiendo de la forma esperada al tratamiento con TB-A (Tabla III). 
Tabla III. Edades, tipo de bruxismo, unidades Speywood de TB-A empleadas y resultados obtenidos en cada paciente tratada en nuestro grupo de estudio.

\begin{tabular}{|l|l|l|l|l|}
\hline N & Años & Tipo de Bruxismo & TBA (US) & resultado \\
\hline 1 & 56 & Nocturno & 50 & 3 \\
\hline 2 & 41 & Nocturno & 45 & 4 \\
\hline 3 & 31 & Diurno y nocturno & 47.5 & 3 \\
\hline 4 & 31 & Diurno y nocturno & 40 & 3 \\
\hline 5 & 41 & Diurno y nocturno & 62.5 & 3 \\
\hline 6 & 36 & Diurno y nocturno & 35 & 3 \\
\hline 7 & 27 & Nocturno & 77.5 & 3 \\
\hline 8 & 41 & Diurno y nocturno & 60 & 4 \\
\hline 9 & 40 & Nocturno & 60 & 3 \\
\hline 10 & 38 & Diurno y nocturno & 85 & 4 \\
\hline 11 & 38 & Nocturno & 70 & 3 \\
\hline 12 & 42 & Diurno y nocturno & 50 & 4 \\
\hline 13 & 39 & Diurno & 40 & 3 \\
\hline 14 & 24 & Diurno y nocturno & 30 & 3 \\
\hline 15 & 26 & Diurno y nocturno & 75 & 3 \\
\hline 16 & 24 & Diurno y nocturno & 62.5 & 3 \\
\hline 17 & 52 & Diurno y nocturno & 45 & 3 \\
\hline 18 & 31 & Diurno y nocturno & 60 & 3 \\
\hline 19 & 67 & Nocturno & 55 & 4 \\
\hline 20 & 33 & Diurno y nocturno & 45 & 3 \\
\hline 21 & 29 & Diurno y nocturno & 65 & 3 \\
\hline 22 & 24 & Diurno y nocturno & 45 & 3 \\
\hline 23 & 39 & Diurno y nocturno & 32.5 & \\
\hline & 27 & Diurno y nocturno & 95 & 32.5 \\
\hline
\end{tabular}

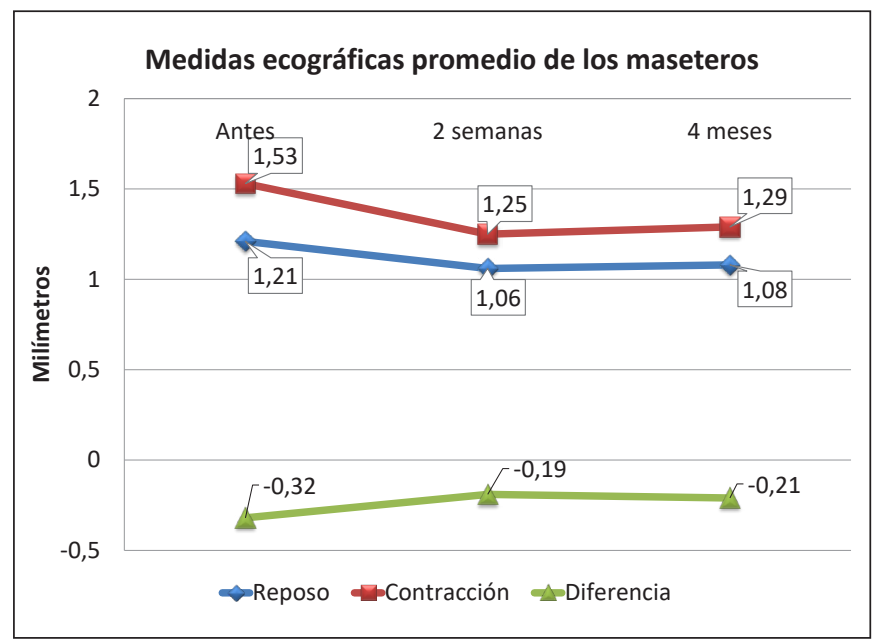

Figura 4. El gráfico muestra la evolución promedio de ambos maseteros, en reposo y contracción, de las medidas obtenidas mediante ecografía.

Respecto a la pregunta sobre si recomendarían el tratamiento: 24 pacientes (96\%) dijeron que lo recomendarían a pesar de haber tenido algún efecto adverso. Solo una paciente, que tuvo dolor moderado durante la inyección y presentó equimosis de más de una semana manifestó que no recomendaría el tratamiento y que no realizaría más sesiones; sin embargo, admitió que mejo-

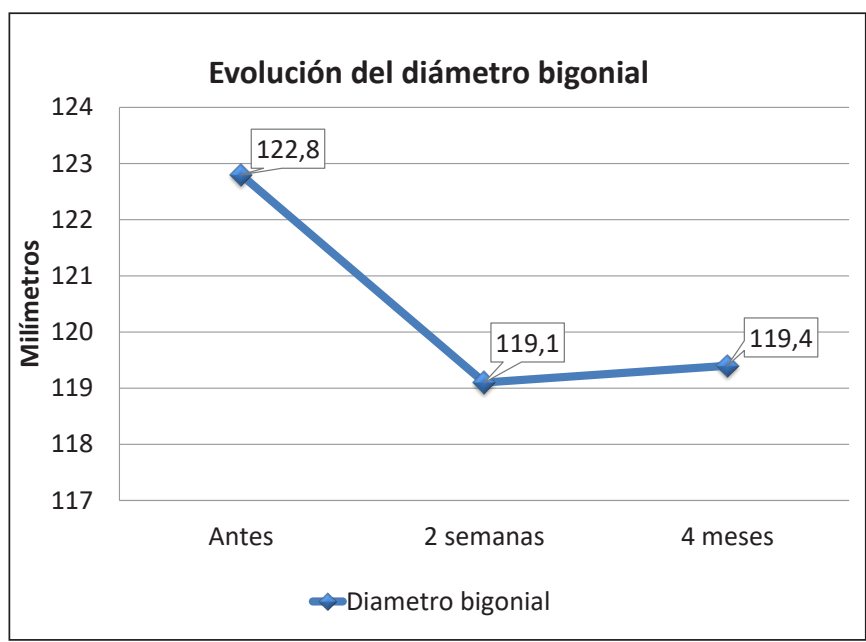

Figura 5. El diámetro bigonial disminuye de forma apreciable 2 semanas después del tratamiento con TB-A. La disminución alcanzada se mantiene sin apenas diferencia 4 meses después.

ró mucho con respecto a su estado inicial. El grado de satisfacción, pacientes satisfechos y muy satisfechos, alcanzó el 96\%; mientras que el 88\% (22 pacientes) expresaron su deseo de continuar con sesiones adicionales de tratamiento en el plazo recomendado inicialmente, no superior a 6 meses para no recaer en los signos y síntomas que presentaban antes del tratamiento. 


\section{Efectos secundarios después del tratamiento}

Tuvimos en cuenta los posibles efectos secundarios, locales y sistémicos, tras el tratamiento con TB-A que en general fueron leves y transitorios. Cuantificamos los efectos adversos en 5 niveles, de 0: sin efectos adversos, hasta 4: muy severos. En el cuestionario tuvimos en cuenta los siguientes síntomas y signos relacionados con el tratamiento:

- Dolor durante la inyección de TB-A. Ninguna de las pacientes informó haber tenido dolor severo o muy severo al inyectar. Solo 5 pacientes $(20 \%)$ informaron de dolor moderado que duró hasta 2 días, mientras que las restantes 20 pacientes ( $80 \%$ ) no tuvieron dolor o fue leve y de duración inferior a 1 día. Es preciso añadir que las pacientes que presentaban dolor antes del tratamiento se vieron libres del mismo después del tratamiento.

- Una paciente (4\%) tuvo equimosis severa que persistió durante 10 días. Dos pacientes $(8 \%)$ tuvieron equimosis moderada y leve que duraron 7 y 5 días respectivamente. Las equimosis solo sucedieron en 1 de los 6 puntos de inyección empleados (fueron 3 por cada masetero). Las restantes pacientes ( $88 \%$ ) no presentaron equimosis.

- Solo 2 pacientes (8\%) informaron haber tenido edema leve que duró 2 días. El resto de pacientes (92\%) manifestaron no haber presentado edema.

- Solo 1 paciente (4\%) refirió haber tenido fatiga muscular severa al masticar durante 20 días, 4 pacientes (16\%) informaron de fatiga leve de menos de 5 días de duración y 20 pacientes $(80 \%)$ permanecieron asintomáticas.

- Ninguna de las pacientes tuvo cambios en la expresión facial.

- Ninguna de las pacientes presentó parestesias.

\section{Resultados fotográficos}

Las fotografías revelaron datos adicionales sobre la forma de la cara. La Fig. 6 muestra la secuencia de 3 controles fotográficos realizados a la paciente $n^{\circ} 24$ del estudio, y corresponden a los controles realizados con los músculos maseteros en relajación y contracción. Esta paciente requirió inyecciones adicionales de TB-A en el control de 2 semanas después del tratamiento inicial, 15 US más por cada lado, quedando libre de BRX y con gran satisfacción por el cambio de la forma de su cara. En la Fig.7, de la misma paciente, la OPG muestra que las superficies mediales de ambos cóndilos presentan importantes cambios degenerativos junto con aplanamiento y desplazamiento de los discos. La escala de desgaste dental clasificó a la paciente como grado 2, pudiendo apreciarse la pérdida del esmalte dental que expone la dentina en un tercio de su superficie. También es de des-

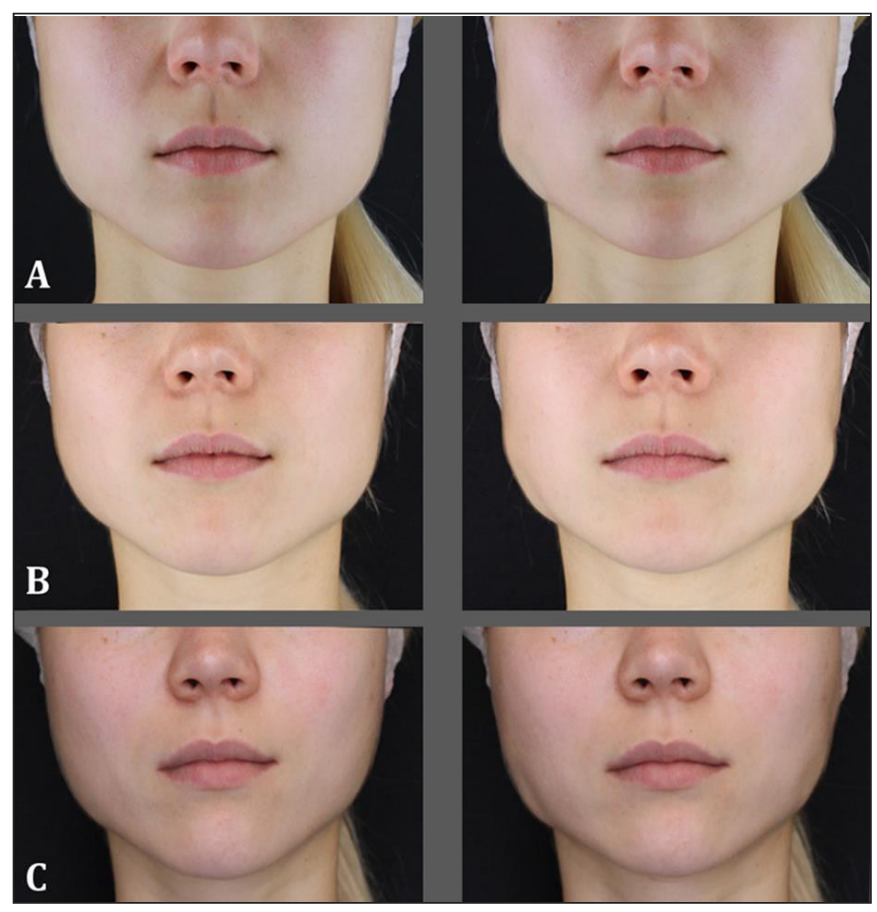

Figura 6. Paciente de 27 años $\left(n^{\circ} 24\right)$ con fotos tomadas en reposo y contracción de los maseteros. A. antes del tratamiento con TB-A. B. 2 semanas después. C. 4 meses después.

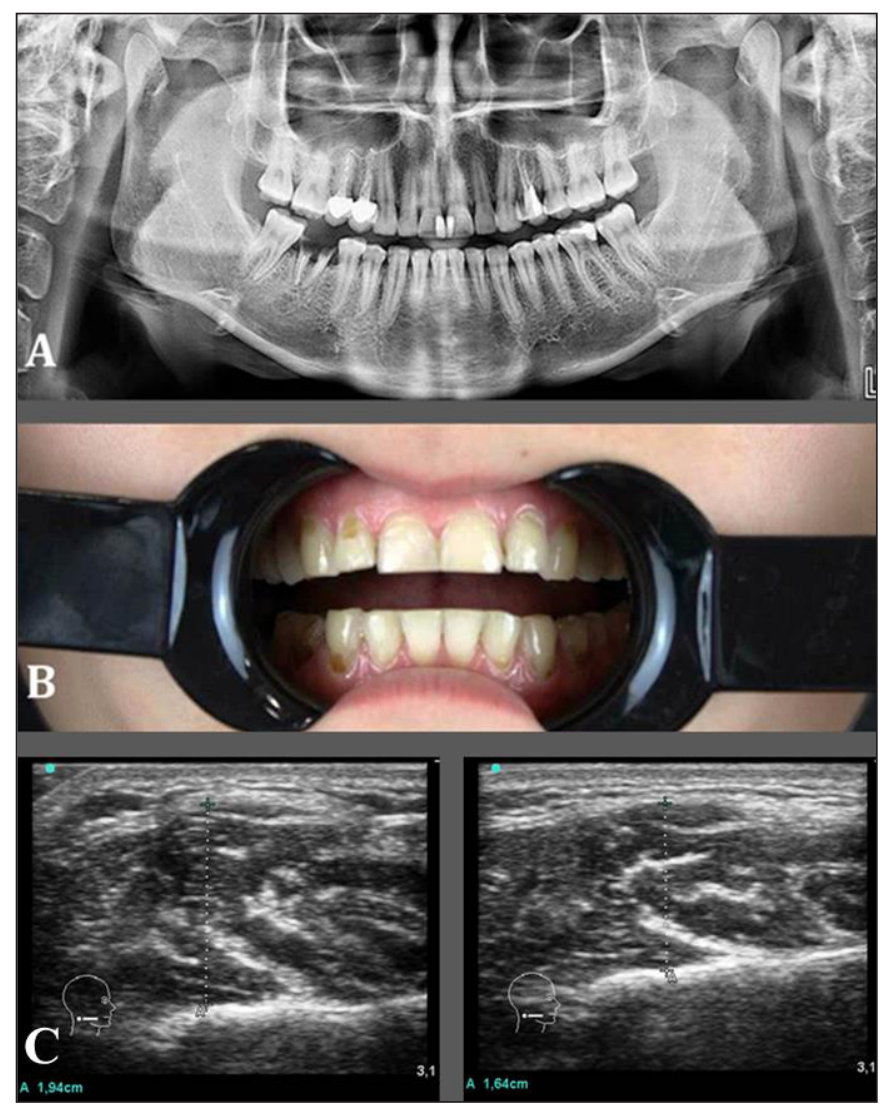

Figura 7. A. Ortopantomografía (OPG) con importantes cambios degenerativos a nivel condilar. B. Índice de desgaste dental de grado 2. C. Disminución del grosor del masetero derecho en $3 \mathrm{~mm}$ medido por ecografía antes y 2 semanas después del tratamiento con TB-A.

tacar la diferencia de medidas obtenidas en relajación y contracción que muestran las ecografías.

La relajación exclusiva de los músculos maseteros mediante la aplicación de TB-A implica beneficios estéticos adicionales al tratamiento del BRX, como pueden 


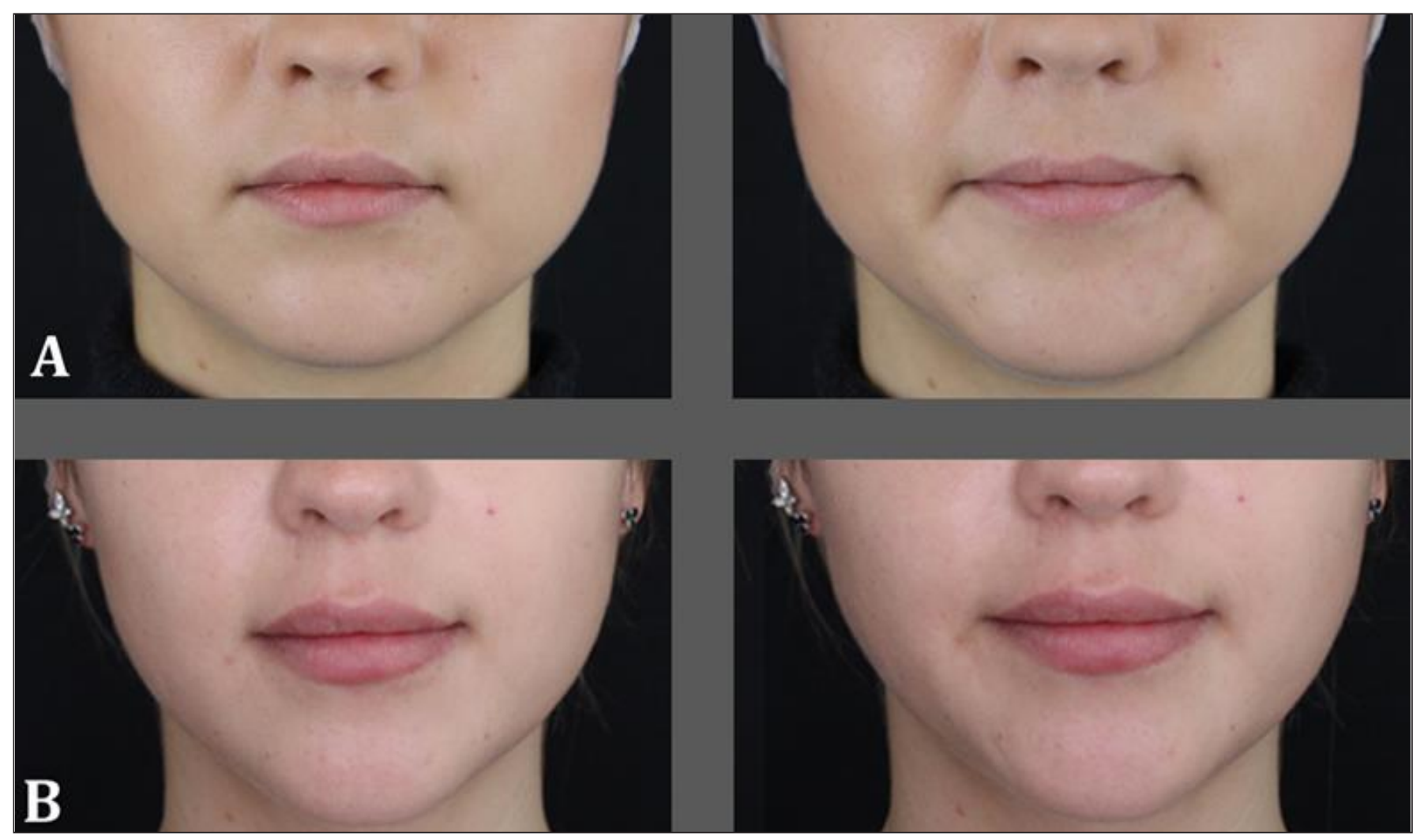

Figura 8. A: Paciente de 24 años ( $n^{\circ} 22$ del estudio) tratada con TB-A. A. Maseteros relajados y en contracción antes del tratamiento. B. Resultado 4 meses después del tratamiento; puede apreciarse no solo relajación a nivel de los maseteros y ángulos mandibulares, sino también en las comisuras de la boca.

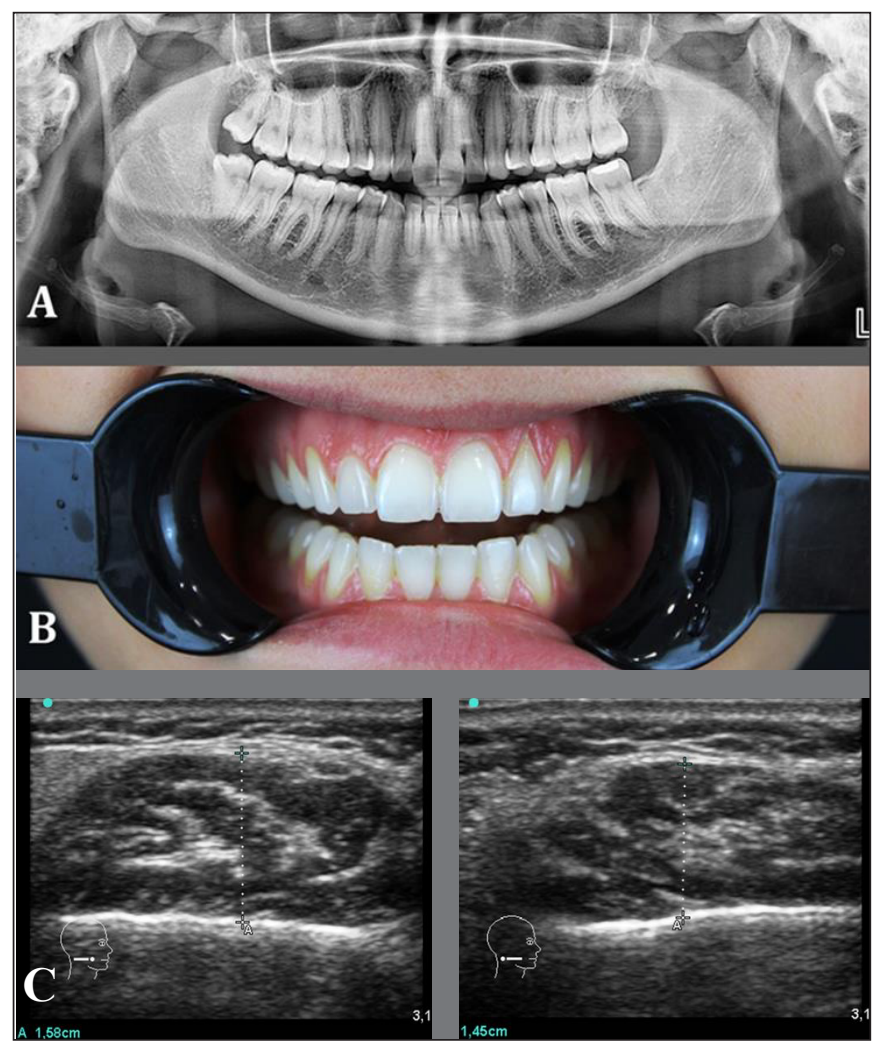

Figura 9. Paciente $n^{\circ}$ 22. A. Disco articular normal en la ortopantomografía (OPG). B. Desgaste dental grado 1, pérdida leve de las características de la superficie del esmalte y pérdida mínima del contorno. C. Medidas ecográficas del masetero derecho en contracción, antes y 4 meses después del tratamiento con TB-A ( $2.3 \mathrm{~mm}$ de diferencia).

apreciarse en la Fig.8, en la que, como beneficio adicional, se logró la relajación de toda la zona orofacial. En este caso consideramos que el tratamiento con TB-A puede tener un carácter preventivo en la evolución del daño inducido por el BRX sobre la ATM, ahora normal, y sobre el índice de desgaste dental, actualmente mínimo. Destacamos que la correlación entre las fotografías, las OPG, el índice de dental y las mediciones obtenidas por ecografía, es muy ajustada en todas las pacientes estudiadas.

\section{Discusión}

En primer lugar, este trabajo sobre el BRX se puede relacionar con los diferentes tipos de diagnósticos utilizados para caracterizar esta patología. Además, este estudio coincide en señalar, en sintonía con lo publicado en la literatura, que el tratamiento con TB-A es uno de los mejores y más simples que puede ofrecerse a los pacientes afectados ${ }^{(20-22)}$. Al ser un estudio realizado fuera de las indicaciones indicadas por la Agencia Española del Medicamento, hemos procurado hacerlo de forma muy rigurosa, tanto en los materiales y método empleados como con la dosificación e inyección de la TB-A en cada paciente del estudio.

Los pacientes que padecen BRX tienen más probabilidades de experimentar dolor y limitaciones en el movimiento de la ATM que aquellos que no lo sufren. Se ha podido constatar una diferencia en el grosor muscular medido por ecografía de pacientes con y sin BRX. El 
grosor del músculo masetero, especialmente en pacientes que muestran hipertrofia muscular, debe considerarse en reposo y en contracción a fin de identificar y tratar a los pacientes susceptibles de verse aliviados de esta afección. ${ }^{(22,23)}$

Algunas investigaciones muestran que la forma más peligrosa de esta patología es el BRX nocturno debido a que tiene un notable componente psicoemocional, aunque también está relacionado con problemas de oclusión dental. ${ }^{(1-3)}$ Nuestro trabajo reveló que el $72 \%$ de las pacientes tenía BRX diurno y nocturno, de las cuales el $84 \%$ tuvo una mejoría significativa y el $16 \%$ restante se vio libre del mismo después del tratamiento con TB-A.

Los resultados alcanzados en las publicaciones consultadas, ${ }^{(2-6)}$ y en ausencia de efectos adversos, muestran que la TB-A debe considerarse un tratamiento de primera línea en caso de BRX. ${ }^{(17,24,25)}$ Teniendo en cuenta que el BRX es más frecuente en la adolescencia, para reducir la patología y sus secuelas en las siguientes décadas de la vida sería conveniente no retrasar un tratamiento que demuestra ser beneficioso en un alto porcentaje de pacientes. El tratamiento temprano del BRX es por tanto deseable y sería una forma adecuada de prevenir alteraciones tanto estéticas como funcionales a corto, medio y largo plazo. No obstante, creemos que precisa información exhaustiva, tanto al menor de edad como a sus padres o representantes legales.

Tal como se dijo, en EE.UU. hay estudios clínicos que sugieren que el estrés sería la razón principal de consulta médica, más que el BRX en sí. ${ }^{(8,9)}$ Es un dato interesante, aunque no se dispone de información contrastada en nuestro país. Sin embargo, en la práctica clínica estomatológica, las quejas habituales de los pacientes son dolor masticatorio, rechinamiento de dientes (muchas veces observado por la pareja de cama) o presencia de hipertrofia muscular de los músculos maseteros en la contracción voluntaria, hecho que puede verificarse mediante medición. ${ }^{(22,23)}$ También debe enfatizarse que en Medicina Estética, las quejas de los pacientes generalmente no son dolor ni ansiedad, sino la percepción de su propia imagen como de cara demasiado "cuadrada". Sugerimos que este motivo de consulta no debería minimizarse y, por el contrario, se tendría que estudiar a fondo a fin de descartar BRX y su patología asociada, como la sobrecarga sobre la ATM en particular o sobre el sistema estomatognático en general.

En relación a lo anterior, hay autores que proponen el uso de antidepresivos tricíclicos y/o ansiolíticos para el tratamiento del BRX, haciendo hincapié en los primeros debido a sus propiedades analgésicas asociadas. ${ }^{(10-12)}$ Así mismo, los agonistas de la dopamina también se han mostrado útiles en el tratamiento porque ayudan a resta- blecer la modulación de las vías dopaminérgicas en los ganglios basales. ${ }^{(25)}$ Sin embargo, la alta prevalencia de BRX entre adolescentes conduce a iniciar tratamientos con antidepresivos y ansiolíticos en edades tempranas, aunque no sería lo más apropiado ni lo más ético debido a sus efectos colaterales desfavorables. ${ }^{(12)}$ De hecho, son medicamentos muy recetados en este grupo de edad a pesar de la falta de estudios rigurosos para respaldarlos; por el contrario, los efectos secundarios son bien conocidos $y$ han sido especialmente evaluados en dicho rango. ${ }^{(10-12)}$

Respecto a las terapias cognitivo-conductuales, se sabe que tienen poco efecto a corto plazo en el manejo del BRX y muchos pacientes abandonan antes de lograr la necesaria relajación; ${ }^{(9)}$ además, muchos estudios realizados tienen bajos niveles de evidencia y se asocian con una escasa calidad metodológica. ${ }^{(8,9)}$ Por lo tanto, si comparamos los tratamientos mencionados (antidepresivos, ansiolíticos, terapias cognitivo-conductuales) con el empleo de TB-A, esta resulta ser una de las mejores opciones para tratar el BRX, tanto por su eficacia como por su rápida respuesta. Obviamente, se deben considerar las alternativas mencionadas si concurren ansiedad y/o depresión valorando adecuadamente el binomio riesgo/ beneficio en el particular caso de los adolescentes.

La TB-A resulta muy cómoda de emplear en pacientes que no precisan otro tipo de medicación, ya que su aplicación se realiza cada 6 meses o más, tiempo durante el cual los pacientes quedan libres de los síntomas acompañantes del BRX al tiempo que se previenen daños acumulativos a la ATM. Diversos estudios han informado que las inyecciones de TB-A son efectivas para controlar los movimientos orofaciales involuntarios, ${ }^{(26,27)}$ además de reducir los efectos adversos ligados a la actividad de los músculos motores de la mandíbula, disminuyendo el nivel de dolor inducido, lo que concuerda con nuestras propias observaciones.

El control de los resultados obtenidos con TB-A a los 4 meses mediante medición ecográfica del masetero en relajación y contracción permite predecir cuándo se debe administrar la segunda inyección, para no inyectar con más frecuencia de la debida. ${ }^{(28)}$ Los pacientes con valores cercanos a los alcanzados en el primer control de tratamiento pueden esperar hasta 2 meses antes de la siguiente inyección; sin embargo, se recomendó a los pacientes con valores cercanos a los que presentaron antes del tratamiento, que realizaran la segunda inyección dentro de un período que no excediera de 1 mes desde este último control (datos no publicados). A fin de elaborar un algoritmo predictivo, este estudio sigue abierto, reclutando nuevos pacientes con un seguimiento más prolongado para evaluar adecuadamente estas recomendaciones que esperamos sean objeto de una nueva publicación. 
En el tratamiento del BRX se ha de tener en cuenta también el examen y valoración ecográfica de la relajación y contracción de los músculos temporales, sin olvidar tampoco que, en el BRX con desplazamiento lateral, los músculos pterigoideos juegan un papel no despreciable. ${ }^{(22,23)}$ Entre nuestras observaciones destaca el hecho de que ninguna de las pacientes tratadas con TB-A a nivel de maseteros precisó inyecciones adicionales en los pterigoideos, aunque el tamaño muestral es reducido.

Las dosis de TB-A utilizadas (media $57 \pm 18$ US) en las pacientes de nuestro estudio son inferiores a las utilizadas en el tratamiento estético del tercio superior de la cara. Además, la posibilidad de migración de la TB-A es muy limitada (aunque recomendamos aspirar previamente antes de llevar a cabo la inyección), ya que se inyecta en el espesor de un solo músculo, de mayor tamaño y grosor comparativamente al resto de los músculos de la cara. Por lo tanto, los efectos adversos, como los mencionados anteriormente, son locales. Los que afectan a la masticación, como la fatiga prematura, suelen ser leves, en casos limitados y se resuelven por completo en pocos días.

Debido al tiempo limitado de seguimiento de las pacientes de nuestro grupo de estudio no nos fue posible estudiar los cambios beneficiosos que pueden ocurrir en el índice de desgaste dental, y lo mismo cabe decir respecto de las alteracionesde la ATM que pudieran observarse a través de la OPG. Los cambios positivos para valorar estos importantes aspectos requieren un período de seguimiento mucho más prolongado y sería deseable para su valoración contar con un grupo más numeroso de pacientes.

\section{Conclusiones}

Las mediciones ecográficas y mediante calibre del diámetro bigonial de los músculos maseteros antes y después del tratamiento con TB-A se correlacionaron en nuestro estudio con la disminución de grosor de dichos músculos y el alivio de los síntomas asociados al BRX en nuestras pacientes.

Durante el tiempo de actuación de la TB-A, estimado entre 5 a 6 meses tras la primera inyección, todas las pacientes tratadas mejoraron significativamente $(76 \%)$ o quedaron libres de BRX (24\%).

Los efectos adversos asociados con este tratamiento fueron leves y se resolvieron en pocos días. Ninguna paciente informó de cambios en su expresión facial.

La TB-A podría proteger las estructuras bucales y faciales (dientes, músculos implicados en la masticación y la propia ATM) del daño inducido por el BRX. No obstante, son deseables nuevos estudios de larga duración y con participación de mayor número de pacientes.
Agradecimientos

A D. Juan Carlos Medina, estadístico, por su inestimable colaboración en el análisis de datos.

\section{Dirección del autor}

\section{Dr. Justo M. Alcolea}

Clínica Alcolea

Plza. Ibiza 4, entlo. $3^{\text {a }}$

08905 L'Hospitalet de Llobregat, Barcelona, España

Correo electrónico: jmalcolea@clinicaalcolea.com

\section{Bibliografía}

1. De Laat A, Macaluso GM. Sleep bruxism as a motor disorder. MovDisord. 2002; 17 Supp12:S67-69

2. Lavigne GJ, Khoury S, Abe S, Yamaguchi T, Raphael K. Bruxism physiology and pathology: an overview for clinicians. $J$ Oral Rehabil. 2008; 35(7):476-494.

3. Lobbezoo F, van der Zaag J, van Selms MK, Hamburger HL, Naeije M. Principles for the management of bruxism. J Oral Rehabil. 2008; 35(7):509-523.

4. Manfredini D, Lobbezoo F. Relationship between bruxism and temporomandibular disorders: a systematic review of literature from 1998 to 2008. Oral Surg Oral Med Oral Pathol Oral Radiol. Endod. 2010; 109(6):e26-50.

5. Lobbezoo F, Brouwers JE, Cune MS, Naeije M. Dental implants in patients with bruxing habits. J Oral Rehabil. 2006; 33(2):152-159.

6. List T, Jensen RH. Temporomandibular disorders: Old ideas and new concepts. Cephalalgia. 2017; 37(7):692-704.

7. C. C. Peck JP, Goulet F, Lobbezoo EL, et al: Expanding the taxonomy of the diagnostic criteria for temporomandibular disorders. J Oral Rehabil. 2014, 41(1): 2-23.

8. Manfredini D, Landi N, Fantoni F, Segù M, Bosco M. Anxiety symptoms in clinically diagnosed bruxers. J Oral Rehabil. 2005; 32(8):584-588.

9 Ommerborn MA, Schneider C, Giraki M, Schäfer R, Handschel J, Franz M, et al. Effects of an occlusal splint compared with cognitive-behavioral treatment on sleep bruxism activity. Eur J Oral Sci. 2007; 115(1):7-14.

10. Falisi G, Rastelli C, Panti F, Maglione H, Quezada Arcega R. Psychotropicdrugs and bruxism. Expert OpinDrugSaf. 2014; 13(10):1319-1326.

11. Herman CR, Schiffman EL, Look JO, Rindal DB. The effectiveness of adding pharmacologic treatment with clonazepam or cyclobenzaprine to patient education and self-care for the treatment of jaw pain upon awakening: a randomized clinical trial. $J$. OrofacPain. 2002; 16(1): 64-70.

12. Cipriani A, Zhou X, Del Giovane C, et al. Comparative efficacy and tolerability of antidepressants for major depressive disorder in children and adolescents: a network meta-analysis. Lancet. 2016. 27; 388(10047):881-890.

13. Rizzatti-Barbosa CM, Nogueira MT, de Andrade ED, Ambrosano GM, de Barbosa JR. Clinical evaluation of amitriptyline for the control of chronic pain caused by temoromandibular joint disorders. Cranio. 2003; 21(3):221-225.

14. Alcolea JM. Actualización sobre aplicaciones de la toxina botulínica en estética facial. Cir. plást. iberolatinoam. 2011; 37(1):8190.

15. Alcolea JM, Trelles MA. Actualización sobre aplicaciones en estética de la toxina botulínica en el tercio inferior de la cara. Cir. plást. iberolatinoam. 2011; 37(2):179-190. 
16. Scott AB. Botulinum toxin injection into extra-ocular muscles as an alternative to strabismus surgery. J PediatrOphthalmol Strabismus. 1980; 17(1):21-25.

17. Glogau R, Biesman B, Kane M. Assessment of Botulinum Toxin Aesthetic Outcomes: Clinical Study vs Real-World Practice. JAMA Dermatol. 2015; 151(11):1177-1178.

18. Brin MF. Botulinum toxin: chemistry, pharmacology, toxicity, and immunology. MuscleNerveSuppl. 1997; 6:S146-168.

19. Schiavo G, Matteoli M, Montecucco C. Neurotoxins affecting neuroexocytosis. Physiol Rev. 2000; 80(2):717-766.

20. Smith BG, Knight JK. An index for measuring the wear of teeth. Br Dent J. 1984; 156(12):435-438.

21. Badel T, Marotti M, Savić-Pavicin I, Zadravec D, Kern J. Radiographic validation of manual functional analysis of temporomandibular joint osteoarthritis. Acta Clin Croat. 2012; 51(1):3542.

22. GollerBulut D, Avci F, Özcan G. Ultrasonographic evaluation of jaw elevator muscles in young adults with bruxism and with and without attrition-type tooth wear: A pilot study. Cranio. 2018; 28:1-8.

23. Najm AA. Sonographic evaluation of masseter muscle thickness in bruxist and non-bruxist subjects. J Bagh College Dentistry. 2014, 26(3):49-52.
24. Chen S. Clinical uses of botulinum neurotoxins: current indications, limitations and future developments. Toxins (Basel). 2012; 4(10):913-939.

25. Lobbezoo F, Lavigne GJ, Tanguay R, Montplaisir JY. The effect of catecholamine precursor L-dopa on sleep bruxism: a controlled clinical trial. MovDisord. 1997; 12(1):73-78.

26. Guarda-Nardini L, Manfredini D, Salamone M, Salmaso L, Tonello S, Ferronato G. Efficacy of botulinum toxin in treating myofascial pain in bruxers: a controlled placebo pilot study. $\mathrm{Cra}$ nio J CraniomandibPract. 2008; 26(2):126-135.

27. Shim YJ, Lee MK, Kato T, Park HU, Heo K, Kim ST. Effects of botulinum toxin on jaw motor events during sleep in sleep bruxism patients: a polysomnographic evaluation. $J$ Clin SleepMed. 2014; 10(3):291-298.

28. González-Magaña F, Miranda LM, Malagón-Hidalgo H, González-Amézquita V. Uso de la toxina botulínica para el tratamiento del músculo masetero. Cir. plást. iberolatinoam. 2012; 38(3):297-302.

\section{Comentario al artículo "Tratamiento del bruxismo con toxina botulínica tipo A. Estudio clínico prospectivo"}

\section{Patricia ERAZO}

Cirujano Plástico, Santos, Brasil.

Directora del Capitulo de Procedimientos no Quirúrgicos de la FILACP (2019-2020)

Bruxismo, término originado del griego brychein, también llamado bruxomanía, neuralgia traumática, neurosis de hábito oclusal, etc; el rechinar de los dientes, como más lo conocemos, representa un problema de tipo traumático por los defectos que puede generar.

En su artículo, Alcolea y Mkhitaryan demuestran, de una manera amplia, el paso a paso en la evaluación de los pacientes tratados con el procedimiento que describen, lo que ayuda a fortalecer el uso de la toxina botulínica A en este tipo de patología con probados y medidos resultados. Cada punto de evaluación fortalece su indicación.

Es muy importarte y claro que el exámen minucioso del paciente es imprescindible para llevar a cabo un buen diagnóstico, clasificar el tipo de alteración que presenta, sentar la indicación correcta del tratamiento y aplicar la dosis necesaria en cada caso. En la actualidad, el uso de toxina botulínica tipo A con dosis de entre 100 a 125 US es un tratamiento efectivo y de fácil ejecución, dentro de todos los que disponemos. En este artículo es importante destacar que la media de unidades empleada fue de $57 \pm 18$ US.

Además de los buenos resultados obtenidos con toxina botulínica, sabemos que el bruximo disminuye en los pacientes adultos y es más intenso a menor edad. Por lo tanto, es siempre importante también el análisis psicológico y el acompañamiento en este tipo de pacientes para no crear falsas expectativas, pues el mayor porcentaje de su etilogía podría ser atribuído a estrés o a altetraciones psicológicas muchas veces no determinadas. Un dato importante a tener en cuenta en la evolución pretratamiento y en la previsión de necesidad de uso del mismo.

Muy interesante por otro lado, marcar las diferencias entre el bruximo diurno y el nocturno, también llamado bruxismo del sueño. El primero, con grado a veces de conciencia, podría ser considerado como un hábito o tic involuntario, mientras que el nocturno es un bruxismo involuntario, que generalmente está relacionado con problemas psicosomáticos y anatómicos, pero también con otros aspectos y hábitos como la edad, la ansiedad, el estrés, algunos transtornos psiquiátricos, o el consumo de alcohol, tabaco y cafeína.

Para contrarrestar además los dolores articulares y las posibles alteraciones témporo-mandibulares que conlleva el bruxismo, sabedores de su etiología no del todo definida y de que no existe una estrategia de tratamiento única, debemos recomendar el acompañamiento terapéutico com medidas de ortodoncia y uso de placas oclusales, e incluso la indicación de benzodiazepinas, anticonvulsivantes, beta-bloqueantes, agentes dopaminérgicos, antidepresivos o relajantes musculares, haciendo énfasis en que ante estos casos, no hay ningún medicamento que sea de primera elección.

Repecto a los 3 puntos de aplicacion de la toxina botulínica tipo A en los vientres del masetero que men- 
cionan los autores en su trabajo, podríamos evaluar en qué casos está indicado realizar la aplicación también en el músculo temporal. Y por otro lado, estar alerta también de que a veces, entre los efectos colaterales provocados por el tratamiento, los pacientes pueden referir boca seca y/o alteración de la sonrisa, dato importante para señalar en los consentimientos informados.

Estamos de acuerdo en que la elección de la toxina botulínica A es la mejor indicación para el tratamien- to del bruximo porque disminuye la actividad excesiva de la musculatura mandibular, y es además un procedimiento de fácil ejecución, con resultados evidentes, especialmente en pacientes que presentan dolor.

Felicitamos a los autores por haber llevado a cabo un análisis minucioso de resultados, que sin duya ayuda a una más correcta indicación y uso del procedimiento y a una mejor previsión de las expectativas de resultados.

\section{Respuesta al comentario de la Dra. P. Erazo}

Justo M. ALCOLEA

En primer lugar agradecemos a la Dra. Patricia Erazo sus acertados comentarios sobre nuestro trabajo. Apreciamos particularmente el reconocimiento al esfuerzo de evaluación del procedimiento y los resultados.

Respecto a las dosis que se mencionan en la literatura cabe comentar que, en general, se han utilizado dosis menores en nuestro estudio. Cuando lo iniciamos éramos conscientes de ello; sin embargo, dado que contábamos con mediciones ecográficas bien ajustadas era oportuno adecuar las dosis de tratamiento en función de los valores tomados en relajación y contracción máxima de los músculos maseteros. Asimismo, nuestra ventaja, en el momento de realizar la inyección, era saber de manera precisa la distancia entre la piel y el espesor del músculo. Creemos que es un dato relevante debido a la difusión más homogénea de la toxina cuando se inyecta teniendo en cuenta ese detalle que si se realiza más superficial o más profunda. De esta forma se pueden optimizar las dosis.

Sin duda una historia clínica exhaustiva es imprescindible, bien orientada a evaluar en cada paciente el estrés, las posibles alteraciones psicológicas o psiquiátricas, consumo de tabaco y otras posibles drogas. Como se comenta en el artículo, en nuestro país es menos habitual que en América la consulta inicial de los pacientes con el psicólogo y, en ese sentido, suelen requerir un refuerzo positivo para que acudan a estos profesionales.

Como bien queda señalado en el comentario, el empleo de la toxina botulínica A de forma aislada no es deseable ni aplicable a todos los pacientes. De ahí la importancia de realizar un seguimiento periódico que puede implementar otras intervenciones, precisamente porque la evolución en el tiempo conlleva modificaciones y ajustes que han de tenerse en cuenta. Por ello es recomendable no iniciar solo con terapia psicológica o antidepresivos y/o ansiolíticos, especialmente en el grupo de pacientes jóvenes, pues en el primer caso los resultados

requieren tiempo y en el segundo debe contarse con los efectos adversos, siendo uno de ellos la posible afectación de la memoria en una época en la que el aprendizaje resulta primordial. Por supuesto, completamente de acuerdo en que el abordaje terapéutico del bruxismo no se haga exclusivamente con toxina botulínica A; aunque estén demostrando buenos resultados estrechamente relacionados con la relajación de los músculos masticatorios.

De los 25 pacientes del estudio, en 5 de ellos evaluamos ecográficamente los músculos temporales en relajación y contracción, aunque no inyectamos porque la relajación obtenida sobre los músculos maseteros conllevó un grado de mejoría en los pacientes que lo hizo innecesario. Es posible que en un estudio con mayor número de pacientes pueda haber casos que requieran de inyecciones adicionales en estos músculos u otros.

Como bien indica la Dra. Erazo, el consentimiento informado debe recoger las posibilidades de sequedad de boca y/o alteración de la sonrisa. En el primer caso, cabría atribuirla a una colocación imprecisa de la toxina botulínica, capaz de afectar glándulas como la parótida o las sublinguales; por ello es importante señalar los puntos de inyección adecuados para no arriesgar inyecciones directas o posible difusión de la toxina. En el segundo caso, podría inyectarse la toxina botulínica A sobre el músculo risorio; también aquí es importante la ecografía, pues el risorio es un músculo inconstante pero identificable cuando existe. Para evitar inyectarlo y la posible asimetría secundaria, es aconsejable realizar la inyección a la profundidad adecuada, en el espesor del músculo masetero y alejados de la fascia superficial para evitar una difusión involuntaria. Obviamente, desaconsejamos cualquier maniobra de masaje en los días posteriores.

Reiteramos nuestro agradecimiento y damos la bienvenida a estos comentarios que, sin duda, harán que mejoremos en nuestro futuro trabajo. 
